\title{
Estigma, medo e perigo: representações sociais de usuários e/ou traficantes de drogas acometidos por tuberculose e profissionais de saúde na atenção básica'
}

\section{Fear, danger, stigma: social representations of drug users and/or dealers affected by tuberculosis and healthcare professionals in primary care}

\section{Jaqueline Teresinha Ferreira}

Universidade Federal do Rio de Janeiro. Instituto de Estudos em Saúde Coletiva. Rio de Janeiro, RJ, Brasil.

E-mail: jaquetfœgmail.com

\section{Elyne Montenegro Engstrom}

Fundação Oswaldo Cruz. Escola Nacional de Saúde Pública. Rio de Janeiro, RJ, Brasil.

E-mail: engstromळensp.fiocruz.br

\section{Correspondência}

Jaqueline Teresinha Ferreira

Rua Raul Pompeia, 144-602, Copacabana. Rio de Janeiro, RJ, Brasil. CEP 22080-00।.

\section{Resumo}

Este artigo apresenta e discute dados de uma pesquisa realizada nas comunidades de Manguinhos, município do Rio de Janeiro, sobre o tratamento da tuberculose no contexto de violência urbana. Para isso, toma-se como base as teorias das ciências sociais e humanas. O estudo aborda as representações sociais que influíram na interação entre os atores envolvidos nesse processo, profissionais de saúde e doentes acometidos por tuberculose e usuários e/ou traficantes de drogas, como resultado de construções históricas e contradições sociais determinadas pelo contexto social de violência em que estavam inseridos. 0 método da pesquisa foi qualitativo, com entrevistas semidiretivas que seguiram um roteiro etnográfico. A interpretação das respostas buscou significados a partir de categorias temáticas, visando sua articulação em categorias mais amplas. Os achados revelaram que as interações entre os usuários e os profissionais de saúde eram determinadas pela forma de perigo, medo e estigma em relação à tuberculose e violência. Palavras-chave: Tuberculose; Violência; Estigma Social; Medo. 


\section{Abstract}

This paper presents and discusses data from a research conducted in the Manguinhos neighborhood communities, municipality of Rio de Janeiro (RJ, Brazil), on tuberculosis treatment within the context of urban violence. For that purpose, social and human sciences theories were considered. The study approaches the social representations that have influenced the interaction between the actors involved in this process, healthcare providers, and people affected by tuberculosis and drug users and/or drug dealers, which are consequence of historic constructions and social contradictions established by the social context of violence where they were inserted. The research method was qualitative, with semidirective interviews following an ethnographic script. The interpretation of the answers searched for meanings based on thematic categories, aiming at their articulation in wider categories. The findings revealed that the interactions between users and healthcare providers occurred under an atmosphere of danger, fear, and stigma in relation to tuberculosis and violence.

Keywords: Tuberculosis; Violence; Social Stigma; Fear.

\section{Introdução}

As políticas públicas de prevenção e controle da tuberculose têm mostrado, historicamente, baixa efetividade, apesar de essa doença ter etiologia, diagnóstico e tratamento conhecidos, além de elevada incidência. Organização Mundial da Saúde estima ocorrerem 10,4 milhões de casos novos de tuberculose em todo o mundo, com 1,4 milhões de óbitos, sendo uma das dez principais causas de morte (WHO, 2016). Situação alarmante também foi evidenciada no Brasil, onde, apesar de queda na taxa de incidência entre os anos 1990 e 2015 - de 51,8/10o mil para 33,6/10o mil habitantes (Brasil, 2016b) -, há elevada carga da doença, com distribuição heterogênea nas regiões e magnitude em grandes centros urbanos, como o Rio de Janeiro, com uma das maiores taxas de incidência da enfermidade e de abandono do tratamento. (Brasil, 2016b). Considerase que a tuberculose é doença negligenciada por se relacionar às condições de pobreza, saneamento deficiente, aglomerados, moradia imprópria, situações que perpetuam um ciclo perverso de iniquidades em saúde, exclusão, estigma (Decit, 2010). Há décadas no país, o Ministério da Saúde (MS), por meio do Programa Nacional de Controle da Tuberculose (PNCT) estabeleceu diretrizes clínicas para o cuidado em toda a rede de saúde, com o Tratamento Diretamente Observado (TDO) como uma das principais estratégias para atingir metas de $85 \%$ de cura, $70 \%$ de detecção de casos e redução em 5\% do abandono do tratamento (Brasil, 2011, 2016a). Para favorecer o êxito das ações, a descentralização da atenção à tuberculose para a Atenção Primária à Saúde (APS) foi implementada, com a oferta de testes diagnósticos, medicação e cuidado em equipe multiprofissional, condições que promovem o vínculo entre usuários e serviços. Dessa forma, a APS, em seu modelo prioritário, a Estratégia de Saúde da Família (ESF), deve se configurar como porta de entrada para o cuidado integral a todos os usuários e estar integrada à Rede de Atenção à Saúde, em caso de necessidade de referência a especialistas. O diagnóstico precoce, o início ágil e a adesão ao tratamento medicamentoso são estratégias efetivas para o controle da doença, bem como a habilidade da equipe de saúde em identificar e lidar com as 
diferentes situações de risco e vulnerabilidade. Adultos jovens, especialmente do sexo masculino, com histórico de abandono do recurso terapêutico, uso de álcool e drogas, coinfecção por HIV e/ou sem TDO foram os que mais mostraram tendência a abandonar o tratamento da tuberculose (Campani; Moreira; Tietbohel, 2011; Herrero et al., 2015; Silva; Andrade; Cardoso, 2013; Silva; Moura; Caldas, 2014). Há que se considerar, ainda, dimensões de vulnerabilidade, quer sejam individuais, sociais ou institucionais, relativas a programas e organização dos serviços de saúde, que devem ser compreendidas em seus contextos e singularidades, para promoção de saúde e cuidado integral (Ayres et al., 2003).

Nessa perspectiva, este estudo analisa dados qualitativos a respeito de pacientes com tuberculose, acompanhados em uma Unidade Básica de Saúde (UBS), que eram usuários e/ou ligados ao comércio ilegal de drogas em Manguinhos, município do Rio de Janeiro (RJ). A comunidade tinha cerca de 40 mil moradores e um dos piores Índices de Desenvolvimento Humano da cidade (IDH=0,726). Como em outras áreas faveladas da cidade, espelhava as mudanças de ordem econômica e social ocorridas no país. O processo de migração, o crescimento urbano acelerado e o empobrecimento das camadas populares, ao longo do tempo, determinavam sua conformação. Pobreza, alcoolismo, violência local, relacionada ao tráfico de drogas, e as frequentes incursões policiais faziam parte do cotidiano dos moradores da região. A tuberculose constituía uma doença com magnitude, conforme dados de estudo epidemiológico realizado no território (348 casos de tuberculose no período de 2004 a 2008 , com proporções elevadas de desfechos negativos, por exemplo, $25 \%$ de abandono do tratamento (Theme Filha et al., 2012). O contexto citado tenderia a contribuir com esses índices, à medida que a associação da tuberculose com drogas, álcool e demais agravos sociais aumenta o risco de contágio, abandono do tratamento e de tuberculose multirresistente (Rehm et al., 2009).

Para aprofundar a compreensão do processo de adoecimento por tuberculose e das relações terapêuticas para o cuidado dessa doença, este estudo apresenta dados relativos às peculiaridades da interação entre pacientes que são usuários e/ou traficantes de drogas e profissionais de saúde da UBS, em um cenário de violência urbana, marcado pelas regras do tráfico de drogas. Os referenciais teóricos das ciências sociais e humanas, notadamente da antropologia e da sociologia, privilegiam as representações sociais dos pacientes e profissionais de saúde sobre a tuberculose, abarcando também as representações sociais dos profissionais em relação a esses pacientes e o modo como isso influi na interação entre eles.

No contexto de Manguinhos, as interações entre os pacientes usuários de drogas e/ou traficantes com instituições e profissionais de saúde eram marcadas por sentimentos de medo e desconfiança em ambos os polos. Os profissionais de saúde revelavam apreensão diante das atividades desses pacientes "perigosos". Aliadas a isso estavam as representações históricas relativas ao estigma dos doentes acometidos por tuberculose, os quais, por sua vez, evitavam serviços e profissionais de saúde, com receio de serem identificados por meio de registros ou denúncias às autoridades policiais. Essas representações estão inscritas em perspectivas macrossociais mais amplas, geradoras de desigualdades e pobreza. Nesse sentido, a globalização neoliberal, cuja premissa é a restrição de investimentos públicos em pesquisas e tratamentos de doenças negligenciadas, como a tuberculose, indica uma política global de exclusão social, perpetuando as condições de doentes dos indivíduos (Cueto, 2015).

O conceito de estigma, numa perspectiva social, foi abordado de forma pioneira por Goffman (2008). Para ele, estigma é uma condição ou característica de um indivíduo não necessariamente física ou visível, que não se coaduna com as expectativas sociais em relação ao seu grupo social. Todas as sociedades definem categorias e atributos dos seus integrantes considerados normais e comuns. O indivíduo estigmatizado, segundo Goffman, é aquele que frustra as expectativas de normalidade da sociedade em que está inserido. Nesse sentido, a história da tuberculose nos mostra como ela passou da romantização literária no século XIX, à imagem de uma doença repulsiva, levando o doente a uma espécie de exílio no século XX. Essa condição estigmatizante responsabiliza os doentes, como se a doença fosse uma falha de caráter, e 
não um problema de saúde pública. A associação entre tuberculose e drogadição potencializa o estigma e nos pareceu digna de ser analisada em sua singularidade.

\section{Metodologia}

Este estudo, de cunho qualitativo, utilizou dados primários de profissionais e de pacientes com tuberculose atendidos em uma UBS de Manguinhos, que na ocasião da coleta (2009) apresentava um modelo híbrido de APS, ou seja, dupla porta de entrada: ESF, com duas equipes, e APS tradicional, com médicos generalistas. Foram realizadas vinte entrevistas semidiretivas com pacientes de tuberculose selecionados a partir do livro Registros de pacientes e controle de tratamento dos casos de tuberculose do ano de $2009^{2}$ e do contato com os profissionais de saúde diretamente implicados na assistência ao paciente tuberculoso e que se dispuseram a participar da pesquisa. Este artigo procura analisar em profundidade dados de uma parcela desses indivíduos, identificados como usuários e/ou traficantes de drogas, seis no total, sendo quatro homens e duas mulheres, na faixa de 19 a 45 anos. No momento da pesquisa, nenhum deles desempenhava atividade remunerada regular. As entrevistas foram realizadas na casa dos pacientes, com duração de cerca de uma hora, e os agentes comunitários de saúde (ACS) foram importantes na mediação e locomoção dos pesquisadores no território. Uma entrevista, excepcionalmente, foi realizada no Centro de Saúde, após a consulta de revisão.

Esse processo seguiu a forma de roteiro etnográfico, em que as entrevistadoras tiveram a oportunidade de desenvolver suas impressões em cada item e observar o modo de vida, bem como as relações familiares e de vizinhança dos pacientes. O emprego dessas técnicas combinadas (entrevista e observação) segue a perspectiva de Beaud (1996), segundo a qual as entrevistas são, por si só, um contexto de observação da cena social, envolvendo espaços e pessoas, e fornecem, assim, elementos para interpretação.
Na entrevista com os pacientes, as variáveis demográficas buscadas foram: sexo, idade e cor da pele. As variáveis socioeconômicas foram: estrutura familiar residencial; escolaridade; religião; renda, ocupação e trabalho; formas de lazer e sociabilidade; percepções sobre a moradia (se saudável ou não) e representações de doenças em geral, a fim de compreender o contexto, o modo de vida, o entendimento sobre a doença e a repercussão dela no cotidiano. Sobre a tuberculose propriamente dita, foram abordadas questões relativas a diagnóstico, relação com profissionais e serviços de saúde, representações sobre a medicação e compreensão do tratamento.

Nas entrevistas com as profissionais de saúde, realizadas em espaços privativos da UBS, buscou-se conhecer as representações delas quanto à doença, adesão e ao abandono do tratamento, bem como suas percepções sobre a relação desses aspectos com seu contexto social e as estratégias mobilizadas e preconizadas para superação das dificuldades encontradas na assistência a tais pacientes. Foram entrevistadas cinco profissionais: médica, enfermeira, psicóloga, técnica em enfermagem e assistente social. Quando as agentes de saúde acompanhavam as entrevistadoras até a moradia dos pacientes, suas atitudes e comentários também nos permitiram vislumbrar algumas representações sobre esses pacientes. Todas as profissionais eram mulheres na faixa etária entre trinta e cinquenta anos, trabalhavam há mais de dois anos na UBS e tinham forte vínculo com a população.

A interpretação das respostas buscou significados a partir da construção de categorias temáticas, visando sua articulação em categorias mais amplas, que se relacionassem com conceitos representativos das teorias das ciências humanas e sociais.

A pesquisa foi aprovada pelo Comitê de Ética em Pesquisa da Escola Nacional de Saúde Pública (ENSP), da Fundação Oswaldo Cruz (Fiocruz), sob o número de protocolo oo38.0.031.00o-o9, e todos os participantes assinaram um termo de consentimento informado. Os nomes aqui usados são fictícios, para preservar o anonimato, evitando

\footnotetext{
2 O livro Registros de pacientes e controle de tratamento de casos de tuberculose faz parte da rotina da Unidade Básica de Saúde, e ali são anotados todos os pacientes com diagnóstico comprovado da doença e seu respectivo endereço.
} 
assim riscos de constrangimento e represálias pelo perfil dessa população.

\section{Resultados e discussão}

As representações sociais estigmatizantes sobre a tuberculose foram construídas no curso da história e influem no processo de acolhimento, uma das tecnologias operacionais que facilitam ou não a acessibilidade aos serviços. É o que desenvolveremos a partir de nossos dados.

\section{Estigma e perigo na interface da assistência ao paciente com tuberculose}

O estigma e medo relacionados à tuberculose perpassaram vários momentos históricos, conforme já relatado. Eles persistem atualmente e se expressam sob diferentes formas, de acordo com o contexto. No que diz respeito às questões estruturais da assistência à tuberculose no Brasil isso não foi diferente. Em nosso campo de pesquisa, foi possível vislumbrar como as representações estigmatizantes relacionadas à tuberculose continuam presentes e se mesclam com as relacionadas à violência local, fatores agravados pelo perfil dos indivíduos entrevistados, potencializando, assim, os sentimentos de medo e perigo em relação a essa alteridade. 0 fato de uma de nossas entrevistadas, Helena, dezenove anos, estudante, recusar-se a ir à escola por medo de ser confundida com "craqueira”, em virtude do emagrecimento decorrente da doença, é ilustrativo de como os sintomas e sinais da tuberculose podem ser interpretados e estigmatizados nesse contexto.

Do mesmo modo, a pesquisa nesses locais e o acesso a determinados pacientes usuários e/ou traficantes de drogas é difícil, pelo medo e pela desconfiança deles diante dos entrevistadores. Nosso trabalho de campo também foi afetado pelo contexto, sendo retardado por vários meses em virtude dos conflitos armados entre policiais e traficantes. Igualmente, os profissionais de saúde hesitavam em nos indicar esses indivíduos e até mesmo em visitá-los, por medo de represálias. Os relatos das entrevistadoras ilustram significativamente esse aspecto:
R. não aderiu ao tratamento. Não quis dar entrevista. No caminho até sua casa, a agente de saúde me avisou que seria difícil conseguir falar com ele, porque ele já havia avisado que não queria mais receber visitas das agentes de saúde. Chegando na casa dele, estava tudo fechado... A ACS me disse que ele estava dentro de casa, mas fingindo que não tinha ninguém. (Entrevistadora 1)

J. não aderiu ao tratamento. A ACS havia se mostrado resistente para indicar a sua moradia, dizendo que só o encontraríamos na "boca de fumo", e lá ela não iria. (Entrevistadora 2)

Segundo Angotti, “o medo da violência é normal, mas entre as classes abastadas ele tem produzido uma paranoia epidêmica condicionada às antigas noções de superioridade baseadas em classe, etnia e gênero" (Angotti, 2013, p. 9). De fato, esses relatos mostram que a "cultura do medo" é uma "linguagem compartilhada" a partir da qual os moradores e profissionais de saúde de Manguinhos tomam precauções, adotam atitudes e comportamentos derivados de inferências sobre práticas e sociabilidades cotidianas (Soares, 1996). É o que observamos nas reticências dos moradores de Manguinhos em deixar as crianças brincarem em determinados espaços, na reclusão desses moradores em suas casas nos períodos de conflito, na abstenção ao trabalho nesses momentos e na suspensão das visitas domiciliares pelos agentes de saúde. Igualmente, a sociabilidade e o uso de serviços também estavam limitados. A entrevista com Mário, ligado ao tráfico, por exemplo, só foi possível em uma das raras vezes que ele visitou o centro de saúde para se consultar. Ele concordou em dar a entrevista, desde que não fosse gravada.

Observamos que, nesses casos, o medo circulava entre os dois polos. Da parte dos doentes, além do receio de serem denunciados à polícia no trajeto ao centro de saúde ou durante o atendimento, havia ainda o medo dos registros. A exigência da notificação compulsória e do preenchimento dos prontuários era considerada perigosa. Da parte dos profissionais, o medo perpassava tanto o plano físico, pelas noções de contágio da doença, quanto o plano moral, pelo contato com indivíduos violentos. 
Por outro lado, a tuberculose propriamente dita e a dificuldade de acesso ao tratamento nos contextos de violência também eram formas de violência. Elias, por exemplo, usuário de drogas e ligado ao tráfico, a despeito de sua condição, concedeu a entrevista ao identificar que os entrevistadores eram "da Fiocruz" vislumbrando assim uma "porta de entrada" ao tratamento. Para Elias, a necessidade e o desejo de se tratar sobrepujavam os possíveis riscos de ser identificado e preso, contrariando o senso comum de que indivíduos em situação de vulnerabilidade não priorizam seus cuidados em saúde.

Conforme já referido, as representações que atravessam a interação entre profissionais do centro de saúde e os pacientes usuários ou traficantes de drogas inscrevem-se em lógicas sociais mais amplas relativas à violência, interferindo no acolhimento dos pacientes para garantir acesso aos serviços. É o que abordaremos.

\section{Os profissionais de saúde e o acolhimento aos "envolvidos"}

O acolhimento, ou seja, a relação entre as atitudes dos usuários sobre os profissionais de saúde e vice-versa nas práticas de assistência como parte integrante do acesso, já foi problematizado em um trabalho de referência de Giovanella e Fleury (1996). Nesse aspecto, Deslandes (2002) observou como a avaliação moral da clientela feita nas emergências revela um julgamento moral dos pacientes, relacionado a raça, modos de falar, de vestir, tipo de emprego, legitimidade dos filhos, situação conjugal e presença de seguro saúde. Estudos como esse revelam que os serviços de saúde discriminam e estigmatizam os pacientes em função de suas características socioeconômicas e culturais, tendendo a não os acolher.

No que concerne à tuberculose, alguns estudos concentram-se na questão da acessibilidade, ou seja, na oferta e organização dos serviços que facilitam ou não seu uso pelos usuários. É o caso dos trabalhos de Arakawa et al. (2011) e Arcêncio et al. (2011). Souza et al. (2007), por sua vez, articulam a questão da violência urbana à tuberculose para entender que essa associação compromete a acessibilidade dos pacientes acometidos pela doença. Tais pesquisas mostram como as dificuldades de organização e oferta de serviços interferem na continuidade do tratamento e são particularmente agravantes da condição desses doentes, gerando assim um círculo vicioso no quadro da tuberculose. 0 relato da técnica de enfermagem revela as vicissitudes da assistência a esses doentes, ilustrando o aspecto em questão:

Eu acho que alguns abandonam [o tratamento] por isso mesmo: o tráfico. Porque eles têm medo até de atravessar a [avenida] Leopoldo Bulhões [...] eles têm muito medo. Aqui, toda hora tem carro de polícia, e alguns deles são bem conhecidos, né?

Sabe-se que a elevada taxa de abandono do tratamento da tuberculose no Brasil é um problema grave e está associada ao risco de formas resistentes da doença e persistência na cadeia de transmissão (Braga et al., 2012). Algumas causas apontadas para a continuidade ou abandono do tratamento são a organização dos serviços e o acolhimento (Ferreira; Engstron; Alves, 2012; Furlan; Oliveira; Marcon, 2012). Todavia, a dimensão simbólica, em que estão presentes questões socioeconômicas e culturais que influenciam o tratamento do indivíduo acometido por tuberculose usuário ou traficante de drogas, ainda carece de estudos.

Conforme já referido, observou-se que o atendimento dos pacientes "envolvidos" com o tráfico estava prejudicado, em função do medo da violência perpetrada por eles. Igualmente, o estigma da doença se fazia presente, dificultando o acolhimento desses doentes. Deslandes observou como os profissionais de emergência interagem com os pacientes perpetuadores de violência:

O julgamento moral dessas vítimas da violência é assunto tabu. Em geral, os profissionais abrem mão da condição de juiz, chegando mesmo a, deliberadamente, evitar saber quem é ou o que fez aquele sujeito, tentando assim alcançar uma maior neutralidade. (Deslandes, 2002, p. 142)

Contudo, a grande maioria dos profissionais da ESF adotava justamente a atitude contrária, ou seja, considerava importante saber distinguir os "envolvidos" e aprender a lidar com eles: 
A questão desse usuário do tráfico, você tem que ter outro olhar. Você tem que atender rápido. Eles chegam e não têm paciência de aguardar: "A senhora vai terminar?", "A senhora pode me atender logo?”. Aí o C. [enfermeiro] já marca logo para o primeiro horário, porque eles vêm, eles querem ser atendidos e ir logo embora. (Assistente social)

Assim, para eles, a deontologia profissional e responsabilidade social em relação ao doente exigiam que fosse facilitado o atendimento. A neutralidade aqui não podia ter espaço. 0 medo de represálias na negativa de atendimento também influía nessa conduta, e ele não é irrelevante, diante de muitas ameaças aos profissionais que se negavam a prestar atendimento.

Por outro lado, alguns desses pacientes se sentiam estigmatizados durante o atendimento e, assim, responsabilizam os profissionais de saúde pelo abandono do tratamento: "Ele [médico] saiu da sala e me deixou sozinho. Quando veio, veio de máscara. Aí eu me senti ofendido: 'Pô, doutor, se eu estou contagioso, o senhor não poderia falar comigo?"' (Luiz, 34 anos). Dessa forma, as precauções em relação ao contágio podem ser interpretadas por esses pacientes como mais um fator de discriminação social, o que atualiza as representações de impureza e perigo ligadas à tuberculose (Douglas, 2016).

Essas representações são igualmente construídas na história, tendo em vista as relações clientelistas e assistencialistas de nosso país, onde o acesso à saúde não é compreendido como questão de direito, mas sim de "boa vontade" e "bom coração" dos profissionais de saúde. Segundo Jobin (2006), a ideologia neoliberal global conduz a práticas de desengajamento do Estado nos campos da ação social, em nome da responsabilização do indivíduo pelos problemas oriundos da pobreza e da desigualdade social. Isso aconteceu também no campo da assistência à saúde, em que há "excesso de responsabilidade" recaindo nos profissionais, o que pode ser observado na amplitude de questões a que eles são demandados (e obrigados a responder) quotidianamente. Esse "excesso" aparece também na complexidade dos processos de decisão, nos quais diversos experts estão implicados e há necessidade de responsabilizá-los pela utilização de recursos financeiros e materiais, num contexto em que são limitados. Enfim, de acordo com o autor, o idioma da responsabilidade pode ser ambíguo, à medida que oscila entre a esfera individual, quanto às causas do problema, e o âmbito coletivo, quanto aos meios e esforços para resolvê-lo. Esse aspecto fica mais claro no caso de Viviane, 29 anos, paciente usuária de drogas.

Os profissionais se referiam a ela como "caso perdido". Segundo a técnica de enfermagem, "Quando ela chega aqui, ela mobiliza todo mundo". O relato da técnica entrevistada trouxe a dimensão do sentimento de frustração do profissional diante desses casos:

$\varepsilon$ difícil, a gente não sabe mais o que vamos fazer, porque a mãe dela morreu de tuberculose, o irmão tem tuberculose, é do tráfico, ela é usuária de drogas. Ela chega aqui morrendo. E assim, já tentaram DOTS, já tentaram tudo. A gente não sabe mais o que fazer, não é? Tem horas em que você vê todo mundo já desesperado, todo mundo já querendo largar, porque não sabe... Já teve internada, já fugiu do hospital, sabe?, tudo. Essa pessoa é aquela que tá pedindo, assim, "eu quero morrer". Vocêfala assim: "Gente, o que éque eu vou fazer?”. A gente fica, assim, sem chão. (Técnica em enfermagem)

Viviane, por sua vez, interpretava as tentativas dos profissionais de atraí-la ao centro de saúde para tomar medicação, conforme preconizado pelas normas do TDO, como punição. Ela nos concedeu entrevista na frente da casa de seu irmão, também usuário de drogas, o qual se recusou a conversar conosco. Segundo ela, seu estado debilitado a impedia de ir ao centro todo o dia para tomar a medicação, como determina o serviço:

Tomava o café de manhã e ficava lá. Tomava outro remédio, vinha a comida, né? Aí depois tomava outro remédio. Aí que eu ia embora. Todo dia era isso, ficar subindo aquela escada, todo dia. Subia aquela escada ali até chorando. Custava dar o remédio prá eu trazer pra casa? Acha que, porque eu tô doente, eu não vou tomar o remédio? Claro que eu vou tomar, 
tenho três filhos prá criar, pô. Eu quero tomar meu remédio. Então, eu errei, porque eu abandonei o tratamento, mas eu não tô correndo atrás de novo? Adona R. [médica] tá me castigando. Tudo bem, ela tá no direito dela, mas, pô, né? Ela não quer dar atenção, pelo menos dá o remédio prá gente tomar em casa, né?

Assim, observamos diferentes lógicas na atribuição da responsabilidade ao seguimento do tratamento, com categorias acusatórias em ambos os polos. A incumbência relativa ao perigo e medo do contágio foi atribuída a diferentes atores no curso da história. À medida que a medicina se tornava mais disciplinadora e normativa, ditando regras de vida saudável e aliada à descoberta do bacilo de Koch no final do século XIX, modificavam-se as políticas de saúde, e o Estado assumiu a responsabilidade pelo controle da doença (Machado et al., 1978). O termo "perigo social" para as doenças contagiosas em geral diz respeito, na verdade, a um controle dos doentes maior que das doenças. Por outro lado, a descoberta de que as condições de moradia e higiene influenciavam a propagação do bacilo comprometeu também o indivíduo na transmissão e no controle da doença, em nome do bem-estar social.

De fato, os casos que envolvem alcoolismo, uso e tráfico de drogas são de difícil manejo para os profissionais, que tentam diferentes estratégias, como buscar parentes, vizinhos e amigos, mas “também depende 'quais' parentes, porque boa parte deles também tem envolvimento" (Técnica em enfermagem). Nesses casos, o esforço empregado é gerador de frustração, uma vez que o resultado é pequeno ou nenhum.

Porque não adianta os profissionais estarem aqui. A gente tá fazendo a nossa parte, a gente acaba fazendo acho que até demais, além do que nós podemos. Por que se a gente gosta de trabalhar com paciente de tuberculose, se envolve muito, mas tem horas que nós temos o nosso limite. (Assistente social)

Esse sentimento é partilhado por grande parte dos profissionais em casos de pacientes ligados ao tráfico, que são identificados como casos de abandono em potencial: "É geralmente assim, quando é do tráfico, a gente já fala logo - 'Ih, esse daí não vai seguir o tratamento"'(Psicóloga). Não obstante, um caso paradigmático é o de Vicente, 31 anos.

Usuário e traficante de drogas, Vicente ficou preso durante treze anos e há dez saiu da prisão. Desde então, nunca mais teve emprego regular, segundo ele, "devido à cadeia”. Assim, ele vive de fazer pequenos "biscates", ocasionalmente, e da pensão da mãe, equivalente a um salário mínimo. Ele nunca frequentou escola, e só sabe escrever o próprio nome. Vicente contraiu tuberculose duas vezes no passado, o que ele atribui ao uso do crack, uma vez que associa tanto a doença quanto a droga à "falta de ar". Logo que os primeiros sintomas e sinais da doença se tornaram visíveis, uma técnica em enfermagem levou-o ao centro de saúde, para realização de exames. Após o diagnóstico, foi internado. Durante a internação, ele contou com a ajuda da profissional, que ia frequentemente visitá-lo e lhe explicava os sintomas e o tratamento. Segundo ele, nunca pensou em desistir de se tratar, e se curou graças ao empenho dessa profissional: "Se não fosse ela, não sei o que seria”.

O caso de Vicente evidencia que a interação do doente com sua rede de relações, como família, vizinhança e profissionais de saúde, é primordial para aceitação da doença e seguimento do tratamento. Estudos têm evidenciado que acolhimento e vínculo são essenciais para o acesso e a adesão ao tratamento em geral (Sá et al., 2007). No caso da tuberculose, isso é particularmente relevante, em virtude das características dessa patologia e de seu tratamento. As representações sociais da doença que perpassam a história, marcadas por estigma de perigo e consequente medo, dificultam a aceitação da doença pelo paciente e sua interação com profissionais de saúde. Além disso, influem na capacidade desses profissionais de estabelecer comunicação efetiva com os pacientes, a fim de desenvolver uma escuta sobre os aspectos ligados à tuberculose para poder, dessa forma, auxiliar os doentes a valorizarem o tratamento e a inseri-lo em seu cotidiano (Ferreira; Engstron; Alves, 2012).

Enfim, as práticas de saúde se fundam no vínculo interpessoal entre paciente e curador, antes mesmo do tratamento seguir uma prescrição qualquer. Melhor dizendo, o curador oferece alguns bens 
ao paciente, como atenção, confiança, palavras e técnica, em troca da doença descrita e apresentada no modelo terapêutico.

\section{Considerações finais}

Como referem Charles Tesser e Armando H. Norman (2014, p. 878): "ao mesmo tempo que o cuidado deve ser prioridade, por mais abrangente, ampliado e de boa qualidade que seja, sabemos que ele não interfere de modo importante em determinantes sociais”. A tuberculose, no contexto local e global, está intimamente relacionada à pobreza, aos problemas sociais e econômicos da população e às iniquidades sociais, que aumentam a probabilidade de contrair a doença e de ela levar à morte. A miséria igualmente impossibilita os doentes de seguirem tratamentos custosos e longos. Por outro lado, a condição de doente tende a piorar a esfera socioeconômica. Os contextos de violência que provocam a "cultura do medo", aliados às representações sociais negativas da doença, configuram-se como agravantes nesse processo, limitando a acessibilidade aos serviços de saúde e interferindo na aceitabilidade entre profissionais de saúde e pacientes.

Observa-se nos serviços de saúde a existência de padrões mais ou menos fixos de representação que os profissionais têm dos usuários, dada à sua condição mais privilegiada na sociedade. Podemos admitir que essas representações têm origem na história de cada um, nas pressões e nos constrangimentos das instituições ou da sociedade, de maneira geral. Nesse sentido, a abordagem qualitativa dos programas de intervenção em saúde torna-se pertinente, à medida que reconhece os contextos material e econômico articulados com os valores de ordem simbólica e social.

A qualidade do cuidado e o sucesso do tratamento perpassam inúmeros aspectos da relação entre o indivíduo com tuberculose e as equipes de saúde, ou seja, o cuidado requer que o profissional converta a dimensão econômica e técnica de seu trabalho em dimensão relacional.

Nossa abordagem partilha dessa análise, por entender que a proposta dos profissionais da ESF se inscreve nesse campo de competência. A ESF é um importante espaço de pesquisa, na medida em que permite, ao mesmo tempo, interação simbólica importante e a efetividade da agenda local do SUS. Assim, a responsabilidade pelo acesso ao tratamento deve ser atribuída aos profissionais de saúde, sem, no entanto, isentar o Estado de seu dever de aplicar políticas mais justas e equitativas. Da mesma forma, a condição estigmatizante da tuberculose e do uso de drogas deve ser superada, e esses problemas precisam ser encarados como questões de saúde pública e não como falhas individuais de comportamento ou caráter.

Este artigo corrobora essa perspectiva e reafirma a importância do trabalho da equipe da ESF e da atenção básica no acompanhamento dos pacientes e do estabelecimento de vínculo entre eles como condição para propiciar uma efetiva continuidade do tratamento. Sugerimos que a situação dos pacientes usuários e traficantes de drogas deve ser contemplada na agenda programática da saúde, como forma de oportunizar o acesso dos doentes aos serviços e fornecer subsídios aos profissionais de saúde que atuam com essa população.

\section{Referências}

ANGOTTI, T. Violence, enclaves, and struggles for land. Latin American Perspectives, Riverside, CA, v. 40, n. 2, p. 5-20, 2013.

ARAKAWA, T. et al. Acessibilidade ao tratamento da tuberculose: avaliação de desempenho de serviço de saúde. Revista Latino-Americana de Enfermagem, Ribeirão Preto, v. 19, n. 4, p. 9941002, 2011.

ARCÊNCIO, R. A. et al. Barreiras econômicas na acessibilidade ao tratamento da tuberculose em Ribeirão Preto - São Paulo. Revista da Escola de Enfermagem da USP, São Paulo, v. 45, n. 5, p.11211127, 2011.

AYRES J. R. C. M. et al. O conceito de vulnerabilidade e as práticas de saúde: novas perspectivas e desafios. In: CZERESINA, D.; FREITAS, C. M. (Org.). Promoção da saúde: conceitos, reflexões, tendências. Rio de Janeiro: Fiocruz, 2003. p. 117-139.

BEAUD, S. L'usage de l'entretien em sciences sociales: playoder pour l'entretien etnographique. Politix, Paris, v. 9, n. 35, p. 226-257, 1996. 
BRAGA, J. U. et al. Fatores associados ao abandono do tratamento da tuberculose nos serviços de atenção básica em dois municípios brasileiros, Manaus e Fortaleza, 2006 a 2008. Cadernos Saúde Coletiva, Rio de Janeiro, v. 20, n. 2, p. 225233, 2012.

BRASIL. Ministério da Saúde. Secretaria de Vigilância em Saúde. Departamento de Vigilância Epidemiológica. Tratamento diretamente observado (TDO) da tuberculose na atenção básica: protocolo de enfermagem. Brasília, DF: Ministério da Saúde, 2011. p. 59-74. (Série F. Comunicação e Educação em Saúde)

BRASIL. Ministério da Saúde. Secretaria de Vigilância em Saúde. Coordenação-Geral de Desenvolvimento da Epidemiologia em Serviços. Guia de vigilância em saúde. Brasília, DF: Ministério da Saúde, Secretaria de Vigilância em Saúde. Coordenação-Geral de Desenvolvimento da Epidemiologia em Serviços, 2016a.

BRASIL. Ministério da Saúde. Secretaria de Vigilância em Saúde. Série histórica da taxa de incidência de tuberculose: Brasil, regiões e unidades federadas de residência por ano de diagnóstico (1990 a 2015). 2016b. Disponível em: <https://goo.gl/j7DTR4>. Acesso em: 3 ago. 2017.

CAMPANI, S. T. A.; MOREIRA, J. S.; TIETBOHEL, C. N. Fatores preditores para o abandono do tratamento da tuberculose pulmonar preconizado pelo Ministério da Saúde do Brasil na cidade de Porto Alegre (RS). Jornal Brasileiro de Pneumologia, Brasília, DF, v. 37, n. 6, p. 776782, 2011.

CUETO, M. Saúde global: uma breve história. Rio de Janeiro: Fiocruz, 2015.

DECIT - Departamento de Ciência e Tecnologia, Secretaria de Ciência, Tecnologia e Insumos Estratégicos, Ministério da Saúde. Doenças negligenciadas: estratégias do Ministério da Saúde. Revista de Saúde Pública, São Paulo, v. 44, n. 1, p. 200-202, 2010.

DESLANDES, S. Frágeis deuses: profissionais da emergência entre os danos da violência e a recriação da vida. Rio de Janeiro: Fiocruz, 2002.
DOUGLAS, M. Pureza e perigo. São Paulo:

Perspectiva, 2016.

FERREIRA, J.; ENGSTRON, E.; ALVES, L. C. Adesão ao tratamento da tuberculose pela população de baixa renda moradora de Manguinhos, Rio de Janeiro: as razões do (im)provável. Cadernos Saúde Coletiva, Rio de Janeiro, v. 20, n. 2, p. 211-216, 2012.

FURLAN, M. C. R.; OLIVEIRA, S. P.; MARCON, S. S. Fatores associados ao abandono do tratamento de tuberculose no estado do Paraná. Acta Paulista de Enfermagem, São Paulo, v. 25, p. 108-114, 2012. Número especial 1.

GIOVANELLA, L.; FLEURY, S. Universalidade da atenção à saúde: acesso como categoria de análise. In: EIBENSCHUTZ, C. (Org.). Política de saúde: o público e o privado. Rio de Janeiro: Fiocruz, 1996. p. 177-198.

GOFFMAN, E. Estigma: notas sobre a manipulação da identidade deteriorada. Porto Alegre: LTC, 2008.

HERRERO, M. B. et al. Social determinants of nonadherence to tuberculosis treatment in Buenos Aires, Argentina. Cadernos de Saúde Pública, Rio de Janeiro, v. 31, n. 9, p. 1983-1994, 2015.

JOBIN, G. Responsabilisation et discours de la responsabilité. In: SAILLANT, F.; GAGNON, E. (Org). De la responsabilité: éthique et politique. Montreal: Liber, 2006. p. 47-59.

MACHADO, R. et al. Danação da norma: medicina social e constituição da psiquiatria no Brasil. Rio de Janeiro: Graal, 1978.

REHM, J. et al. The association between alcohol use, alcohol use disorders and tuberculosis (TB): a systematic review. BMC Public Health, London, n. 9, p. 1-12, 2009.

SÁ, L. D. et al. Tratamento da tuberculose em unidades de saúde da família: histórias de abandono. Texto \& Contexto Enfermagem, Florianópolis, v. 16, n. 4, p. 712-718, 2007.

SILVA, C. C. A. V.; ANDRADE, M. S.; CARDOSO, M. D. Fatores associados ao abandono do tratamento de tuberculose em indivíduos acompanhados em unidades de saúde de referência na cidade do Recife, Estado de Pernambuco, Brasil, entre 
2005 e 2010. Epidemiologia e Serviços de Saúde, Brasília, DF, v. 22, n. 1, p. 77-85, 2013.

SILVA, P. F.; MOURA, G. S.; CALDAS, A. J. M.

Fatores associados ao abandono do tratamento da tuberculose pulmonar no Maranhão, Brasil, no período de 2001 a 2010. Cadernos de Saúde Pública, Rio de Janeiro, v. 3o, n. 8, p. 17451754, 2014.

SOARES, L. E. (Org.). Violência e política no Rio de Janeiro. Rio de Janeiro: Relume-Dumará: Iser, 1996.

SOUZA, F. B. A. et al. Peculiaridades do controle da tuberculose em um cenário de violência urbana de uma comunidade carente do Rio de Janeiro.
Jornal Brasileiro de Pneumologia, Brasília, DF, v. 33, n. 3, p. 318-322, 2007.

TESSER, C. D.; NORMAN, A. H. Repensando o acesso ao cuidado na Estratégia Saúde da Família. Saúde e Sociedade, São Paulo, v. 23, n. 3, p. 869883, 2014.

THEME FILHA, M. M. et al. Análise da tuberculose em uma unidade de Atenção Primária à Saúde na cidade do Rio de Janeiro: perfil clínico, resultado de tratamento e qualidade dos registros. Cadernos Saúde Coletiva, Rio de Janeiro, v. 20, n. 2, p. 16976, 2012.

WHO - WORLD HEALTH ORGANIZATION. Global tuberculosis report 2016. 21. ed. Genève: WHO, 2016.

\section{Agradecimentos}

Agradecemos a Luciana Correia Alves, pela participação na concepção e no desenho desta pesquisa, e a Zaira Bosco e Rachel Barros, pela realização das entrevistas.

\section{Contribuição das autoras}

Ambas as autoras participaram do planejamento e da execução da pesquisa, desde a análise dos dados à redação do artigo.

Recebido: 21/10/2015

Reapresentado: 26/08/2017

Aprovado: 18/10/2017 